\title{
NOVO REGISTRO DE CYPELLA SECT. CYPELLA (IRIDACEAE: TIGRIDIEAE) PARA O BRASIL ${ }^{1}$
}

\author{
LEONARDO PAZ DEBLE ${ }^{2,3}$, ANABELA SILVEIRA DE OLIVEIRA DEBLE ${ }^{4}$, \\ FABIANO DA SILVA ALVES 5
}

\section{RESUMO}

Durante excursões de coleta no oeste do Rio Grande do Sul foi constatada a ocorrência de Cypella armosa Ravenna, sendo esta espécie adicionada à flora autóctone brasileira. Cypella armosa é facilmente separada das demais espécies pelo tamanho de suas flores (48-65 mm de diâmetro), pela cor amarelo-clara ou amarela do perigônio e pelas cristas adaxiais do ginoécio com 5.5-7.5 mm de comprimento. Cypella armosa está relacionada à $C$. exilis Ravenna; esta espécie separa-se, todavia, de $C$. armosa pelo menor porte, pelo perigônio alaranjado, de 38-48 mm de diâmetro, e pelas cristas do ginoécio, de 4-5 mm de comprimento. C. armosa é descrita, ilustrada e comparada com táxones afins; são também fornecidos: mapa de distribuição geográfica, dados ecológicos e status de conservação da espécie.

Palavras-chave: Biodiversidade, Cypella armosa, Cypurineae, Flora do Brasil, Taxonomia.

\section{ABSTRACT}

[New record of Cypella sect.Cypella (Iridaceae: Tigridieae) from Brazil].

During trips in the west of Rio Grande do Sul State, Brazil, it was found Cypella armosa Ravenna, being this species added to native brazilian Flora. Cypella armosa is easily segregated from all species of Cypella by size of flowers (48-65 mm diameter), light-yellow or yellow perigone, and gynoecium cristae measuring 5.5-7.5 mm long. Cypella armosa is most closely related to C. exilis Ravenna, but this species is separated from $C$. armosa by smaller habit, orange perigone with $38-48 \mathrm{~mm}$ in diameter, and gynoecium cristae measuring 4-5 mm long. C. armosa is described, illustrated and their taxonomic affinities are assessed; the map of geographical distribution, ecological data, and conservation status are also provided.

Key words: Biodiversity, Brazilian Flora, Cypella armosa, Cypurineae, Taxonomy.

\section{INTRODUÇÃO}

Cypella Herb. (Iridaceae: Tigridieae) inclui cerca de 25 espécies de plantas bulbosas, providas de folhas plicadas, com distribuição geográfica na Argentina, Brasil, Uruguai e Paraguai (Ravenna, 2009). A maior diversidade de espécies e endemismos é verificada no nordeste da

Recebido em 15-5-2012 e aceito para publicação em 25-5-2012.

2 Curso de Ciências da Natureza, Universidade Federal do Pampa, UNIPAMPA. Av. 21 de Abril, 80, Dom Pedrito, Rio Grande do Sul, 96450-000, Brasil.

3 Autor para correspondência: deble.biol@gmail.com

${ }^{4}$ Curso Superior de Tecnologia em Gestão Ambiental, Universidade da Região da Campanha, URCAMP. BR 293, KM 238, Dom Pedrito, Rio Grande do Sul, 96450000, Brasil.

5 Curso de Ciências Biológicas, Universidade da Região da Campanha. Praça Getúlio Vargas 47, Alegrete, Rio Grande do Sul, 97542-570, Brasil. argentina e áreas próximas (Deble, 2012). Para o Brasil são reconhecidas 13 espécies e duas subespécies (Eggers, 2012).

Os limites genéricos de Cypella são motivos de divergência entre diferentes autores. O gênero foi fundado por Herbert (1826), com base em Tigridia herbertii, espécie anteriormente descrita pelo mesmo autor em "Botanical Magazine" (1825) e transferida para Moraea por Lindley (1826). Klatt $(1862,1871)$ reservou o nome genérico Cypella para espécies atualmente subordinadas a Neomarica; o autor reconheceu Polia Tenore (1845: 92) como gênero válido e, nesse nome, incluiu quatro espécies atualmente reconhecidas em Cypella.

Baker (1877) abordou Cypella com a opinião estabelecida anteriormente por Herbert. No "Handbook of Irideae", Baker (1892), no entanto, ampliou o conceito genérico de Cypella 
e incluiu Larentia Klatt (1882: 362) e Phalocallis Herbert (1839: t. 3710) na sinonímia do gênero. Foster (1945) também reconheceu Hesperoxiphion Baker (1877: 76) como sinônimo nomenclatural de Cypella. Ravenna (1964) aceitou, inicialmente, o conceito amplo de Cypella, e tratou Phalocallis como subgênero subordinado. Em trabalhos posteriores, Ravenna (1977, 1981a, 1981b, 1983) tratou Phalocallis, Larentia e Hesperoxiphion como gêneros independentes, e descreveu Kelissa Ravenna (1981c: 106), Catila Ravenna (1983: 197) e Onira Ravenna (1983: 204), gêneros monotípicos, morfologicamente relacionados à Cypella.

Catila foi transferido por Goldblatt \& Henrich (1991) para Calydorea Herbert (1843: 85). Roitman \& Castillo (2007), Roitman, Maza \& Castillo (2008) e Goldblatt \& Manning (2008) reduziram Phalocallis, Kelissa e Onira à sinonímia de Cypella. Larentia e Hesperoxiphion, entretanto, são reconhecidos como válidos no "The Iris Family" (Goldblatt \& Manning, 2008). Em recente contribuição, Ravenna (2009) reabilitou todos esses gêneros e também estruturou chave para a separação de Cypella de gêneros afins.

Ravenna (1981b: 20-21) descreveu Cypella armosa tendo por base coleções realizadas nas províncias argentinas de Chaco, Corrientes, Formosa, Misiones e Santa Fé, além dos distritos de Guairá (Villa Rica) e Cordillera (São Bernardino), no Paraguai. Desse último local, o próprio Ravenna coletou o material que foi escolhido como holótipo. $\mathrm{O}$ autor inseriu a nova espécie na seção Cypella, e, pelas anteras e forma do androginoécio, relacionou $C$. armosa com C. exilis Ravenna (1981a: 492), da qual, conforme Ravenna "It departs from that species in the taller habit, larger flowers of a different color, and larger anthers and style-arms".

Em contribuição posterior, Ravenna (2009) descreveu Cypella trimontina Ravenna (2009: 2), da qual relacionou pelo hábito com $C$. armosa, separando a nova espécie pelas flores menores, alaranjadas e com cristas mais curtas. No mesmo trabalho, Ravenna revalidou $C$. amambaica Ravenna (2009: 4), espécie que compartilha com C. armosa a cor amarela das flores, mas, conforme o autor, separa-se por apresentar "small size of all floral parts".

Tendo por base o "Catálogo de las Plantas Vasculares del Cono Sur" (Roitman, Maza \& Castillo, 2008), a "Lista de espécies da Flora do Brasil" (Eggers, 2012), a bibliografia específica sobre o gênero Cypella, além de coletas próprias, verificou-se uma lacuna de dados referentes às espécies de Cypella que crescem no Rio Grande do Sul, especialmente em áreas campestres do oeste e metade sul do estado. Este trabalho tem por finalidade registrar Cypella armosa como nativa na flora sul-rio-grandense.

\section{MATERIAL E MÉTODOS}

Foram realizadas excursões de coleta em todas as regiões fisiográficas do Rio Grande do Sul (Fortes, 1979). Os indivíduos coletados foram georreferenciados, fotografados e identificados através de consulta bibliográfica e consulta a tipos depositados em herbários nacionais e internacionais. As coletas foram depositadas no Herbário SI para fins de registro; no caso de duplicatas, foram enviadas a outras instituições. Para a realização deste estudo foram analisadas exsicatas dos seguintes herbários: CTES, HAS, HBR, FLOR, ICN, PACA e SI (Thiers, 2011). Na descrição morfológica foram utilizadas as terminologias adotadas por Ravenna (1981a, 1981b), Chukr \& Capellari Jr. (2003) e Goldblatt \& Manning (2008). Para as ilustrações foram utilizados lupa binocular QUIMIS 766, com câmara clara acoplada, e material vivo, cultivado a partir de bulbos coletados em São Borja. As fotos foram obtidas no local de ocorrência da espécie, com máquina fotográfica SONY DSC-W210. Em todos os locais de ocorrência da espécie foram registradas as coordenadas geográficas de cada sítio, mediante aparelho GPS (Sistema de Posicionamento Global) Garmin eTrex 30, com precisão métrica de três metros. Em laboratório, utilizando-se do Software GPS Track Maker Professional, GTM PRO, versão 4.8 (desenvolvido por Odilon 
Ferreira Júnior), todas as coordenadas registradas em campo foram lançadas em base cartográfica regional, previamente selecionada e determinada a partir da Base Cartográfica Vetorial Contínua do Rio Grande do Sul (Hasenack \& Weber, 2010). Com a compilação destes dados, juntamente com as informações levantadas em campo, elaborou-se o mapa de localização geográfica dos locais de ocorrência da espécie em questão. Por fim, este mapa, gerado em arquivo formato GTM (GPS TrackMaker) foi transformado em arquivo formato Autocad DXF (Drawing Interchange Format/Drawing Exchange Format) e transferindo ao software Corel DRAW X5 (Software desenvolvido pela Corel Corporation, 2010), para a edição gráfica final.

\section{RESULTADOS E DISCUSSÕES}

Cypella armosa Ravenna, Wrightia 7 (1): 20. 1981. Tipo: Paraguai, Cordillera "In herbosis inundatis pr. San Bernardino Paraguariae" II1966, P. F. Ravenna 462. (Holótipo: Herb. Ravenna; Isótipo: K, photo!). Figuras 2, 3 (a-c).

Planta de 40-60 cm de altura, com caule subterrâneo de até $10 \mathrm{~cm}$ de comprimento. Bulbo ovóide, catáfilos enegrecidos, $9-20 \mathrm{~mm} \times 8-20$ $\mathrm{mm}$, prolongando em curto colar. Folhas na antese 1-2; lâmina foliar estreitamente linear, plicada, aguda no ápice, $12-30 \times 0.2-0.4 \mathrm{~cm}$. Espatas 3, verdes ou pálido-esverdeadas, 2 valvadas, pedunculadas, portando uma flor; valvas externas de $2.1-2.8 \mathrm{~cm}$ de comprimento, as internas de 4-5.6 cm de comprimento, ambas membranáceas e amarronzadas nas extremidades. Perigônio amarelo-claro ou amarelo, com pontos e faixas púrpuras concentradas na base, radialmente simétrico, com 48-65 mm de diâmetro. Série de pétalas dissimilar: pétalas externas espatuladas, patentes, $36-38 \mathrm{~mm} \times 12$ $16 \mathrm{~mm}$, base côncava com 10-15 mm, com pontos e faixas púrpuras concentradas na metade proximal. Pétalas internas arqueadas, geniculado-reflexas, unguiculadas em direção à base, 14-18 mm $\times 10-12 \mathrm{~mm}$, com faixas púrpuras na metade proximal, e faixas oblíquas e pontos púrpuro-escuros, e mancha central branco-creme na parte distal; unguículo de 7-9 $\mathrm{mm} \times 2$ $2.5 \mathrm{~mm}$. Filamentos branco-creme ou amarelados, dilatados em ambas as extremidades, com 3-3.5 mm de comprimento; anteras linearoblongas, 7-8 $\mathrm{mm} \times 1.4-1.6 \mathrm{~mm}$; conectivo branco-creme, pólen e lóculos escuros. Ovário esverdeado, $7-8 \mathrm{~mm} \times 2.5-3 \mathrm{~mm}$. Estilete de 4-4.8 $\mathrm{mm}$ de comprimento. Ramas oblíquas, conduplicadas, 6-7 mm de comprimento; cristas três, aurantíacas, as adaxiais agudoacuminadas, de 5.5-7.5 mm de comprimento, a abaxial bilobada de $1 \mathrm{~mm}$. Cápsula obovada, 12 $16 \mathrm{~mm} \times 7-8 \mathrm{~mm}$. Sementes oblongas ou obcônicas, anguladas, marrom-avermelhadas, epiderme estriada, cerca de $2 \mathrm{~mm}$ de comprimento.

Distribuição \& habitat: conforme Ravenna (1981b: 20-21, 2003), Cypella armosa ocorre nas províncias argentinas do Chaco, Corrientes, Formosa, Misiones e Santa Fé, além dos distritos de Cordillera (São Bernardino) e Guairá (Villa Rica), no Paraguai (Figura 1). Trata-se de espécie típica de campos úmidos e banhados ao longo das bacias dos rios Paraná e Paraguai, sendo táxon relativamente comum nestes locais; mais rara na bacia do rio Uruguai, também se encontra em pontos isolados, principalmente nas proximidades de San Tomé e Hormiguero (Argentina), atingindo seu limite oriental de distribuição no oeste do Rio Grande do Sul, nos municípios de Garruchos e São Borja (Figura 1).

Fenologia: Cypella armosa floresce e frutifica durante o final da primavera-verão. As flores abrem-se ao amanhecer e fecham-se antes do meio-dia.

Conservação: de acordo com material examinado, a espécie é considerada não ameaçada, conforme critérios utilizados pela IUCN (2010). Cabe salientar que no território brasileiro as populações estão reduzidas ao oeste do Rio Grande do Sul, em área inferior a $1000 \mathrm{~km}^{2}$, sendo espécie rara na flora regional (Figura 1).

Comentários: Cypella armosa é facilmente separada das demais espécies pelo tamanho de suas flores (48-65 mm de diâmetro), pela cor 


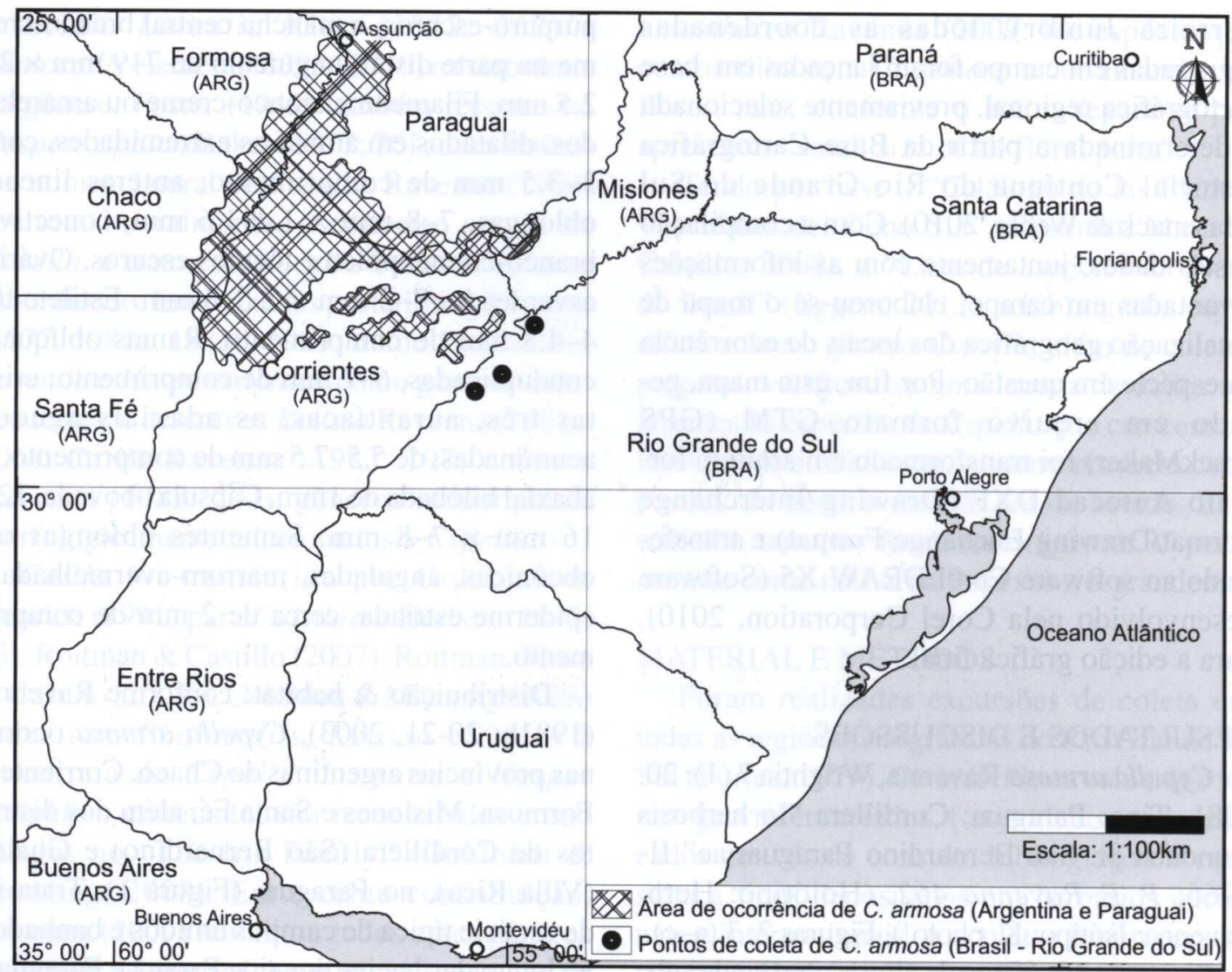

FIGURA 1 - Mapa de distribuição geográfica de Cypella armosa.

amarelo-clara a amarela do perigônio e pelas cristas adaxiais do ginoécio com 5.5-7.5 mm de comprimento (Figura 3a-c). Cypella exilis Ravenna é a espécie mais afim, mas separa-se de $C$. armosa pelo menor porte, pelo perigônio alaranjado, de 38-48 mm de diâmetro, e pelas cristas do ginoécio, de 4-5 mm de comprimento (Figura 3d-e). Cypella trimontina Ravenna é outra espécie similar, mas separa-se pelas folhas linear-elípticas, com 0.4-0.6 mm de largu$\mathrm{ra}^{6}$, pelo perigônio alaranjado, pelas cristas do ginoécio de $2.5-3 \mathrm{~mm}$ e pelos estames com filamentos de 4-5 mm de comprimento. Cypella armosa pode ser separada de $C$. exilis e $C$. trimontina com base nos caracteres da Tabela 1.

${ }^{6} \mathrm{Na}$ descrição original, Ravenna (2009: 2) citou folhas com 0.1-0.2 mm de largura; no entanto, na análise do tipo, verifica-se que as folhas têm largura de 0.4-0.6 mm.
Material examinado: BRASIL. Rio Grande do Sul: Garruchos, em campo hidromórfico, flores amarelo-claro, manchadas de vinho, [28¹1'49.75’S, 55³6'59.29”'W], II-2006, L. P. Deble \& A. S. Oliveira-Deble 7183 (SI). São Borja, em banhado, na margem esquerda do rio Butuí [ $28^{\circ} 57^{\prime} 44.60^{\prime \prime}$, $56^{\circ} 12^{\prime} 47.29^{\prime \prime}$ ], II2006, L. P. Deble \& A. S. Oliveira-Deble 7184 (SI). Em campo hidromórfico e banhado, ao sul da cidade de São Borja [28 $46^{\prime} 49.43^{\prime \prime}$, $\left.56^{\circ} 02^{\prime} 36.08^{\prime \prime} \mathrm{W}\right], 13-\mathrm{III}-2007$, L. P. Deble \& A. S. Oliveira-Deble 7704 (SI).

Material adicional examinado: ARGENTINA. Chaco: Colonia Benitez, 16-V-1959, A. G. Schulz 10410 (CTES, SI). Corrientes: Concepción, flowers lemon-coloured, grassland on medium-high to fairly low ground, sandy soil, 22-II-1988, T. M. Pedersen 15126 (CTES). Corrientes, en pradera, orilla del arroyo, 12-X- 


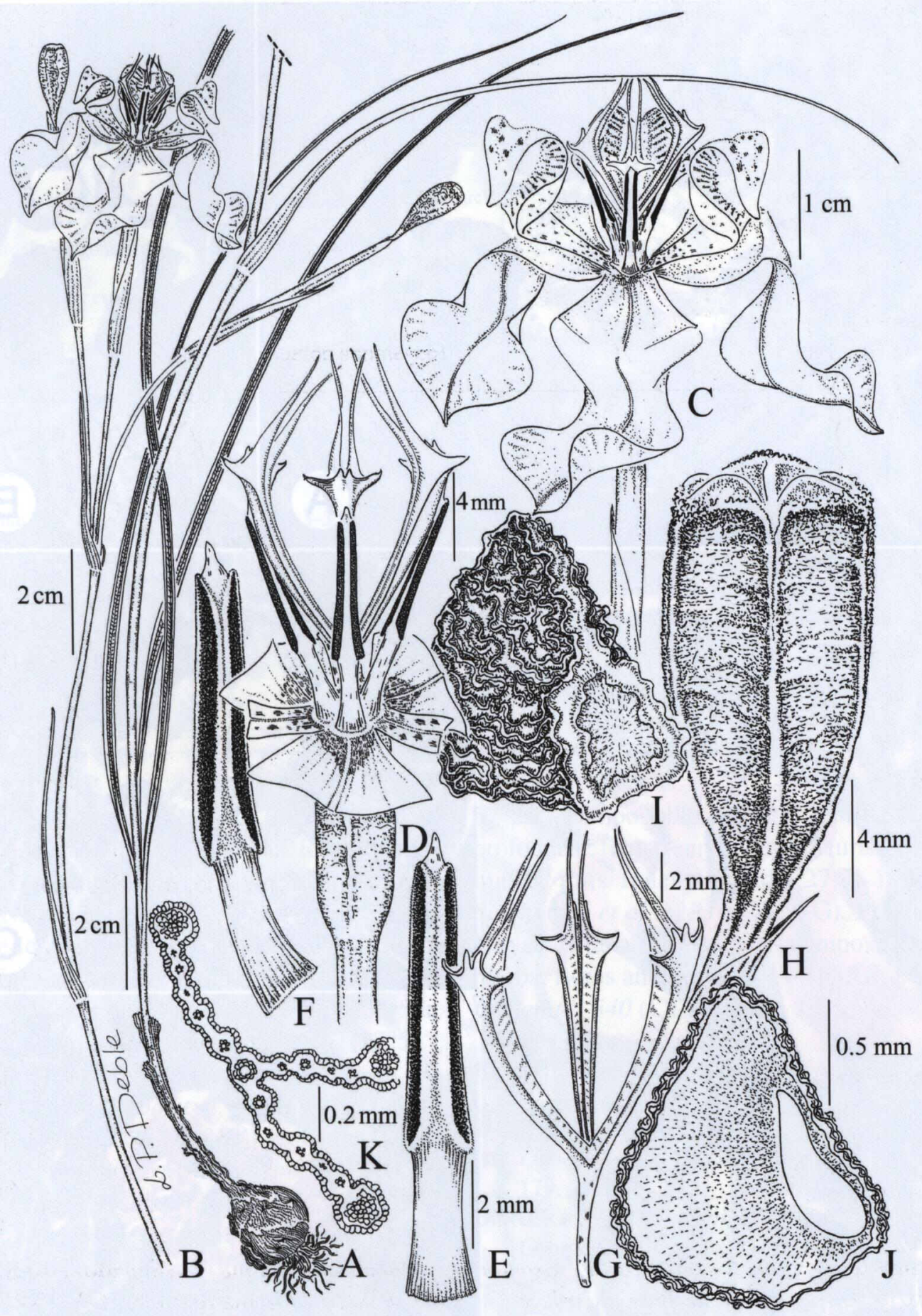

FIGURA 2 - Cypella armosa. A - Parte basal da planta. B - Ramo florido. C - Flor. D - Flor com o perigônio removido. E - Estame vista dorsal. F - Estame vista frontal. G - Ginoécio. H - Cápsula. I - Semente. J - Semente em corte longitudinal. $\mathrm{K}$ - Corte transversal da folha na parte mediana da lâmina. Barra de escala próxima a letra "E" para $\mathrm{Fe}$ próxima a letra "H" para I (A-K de Deble \& Oliveira-Deble 7184). 


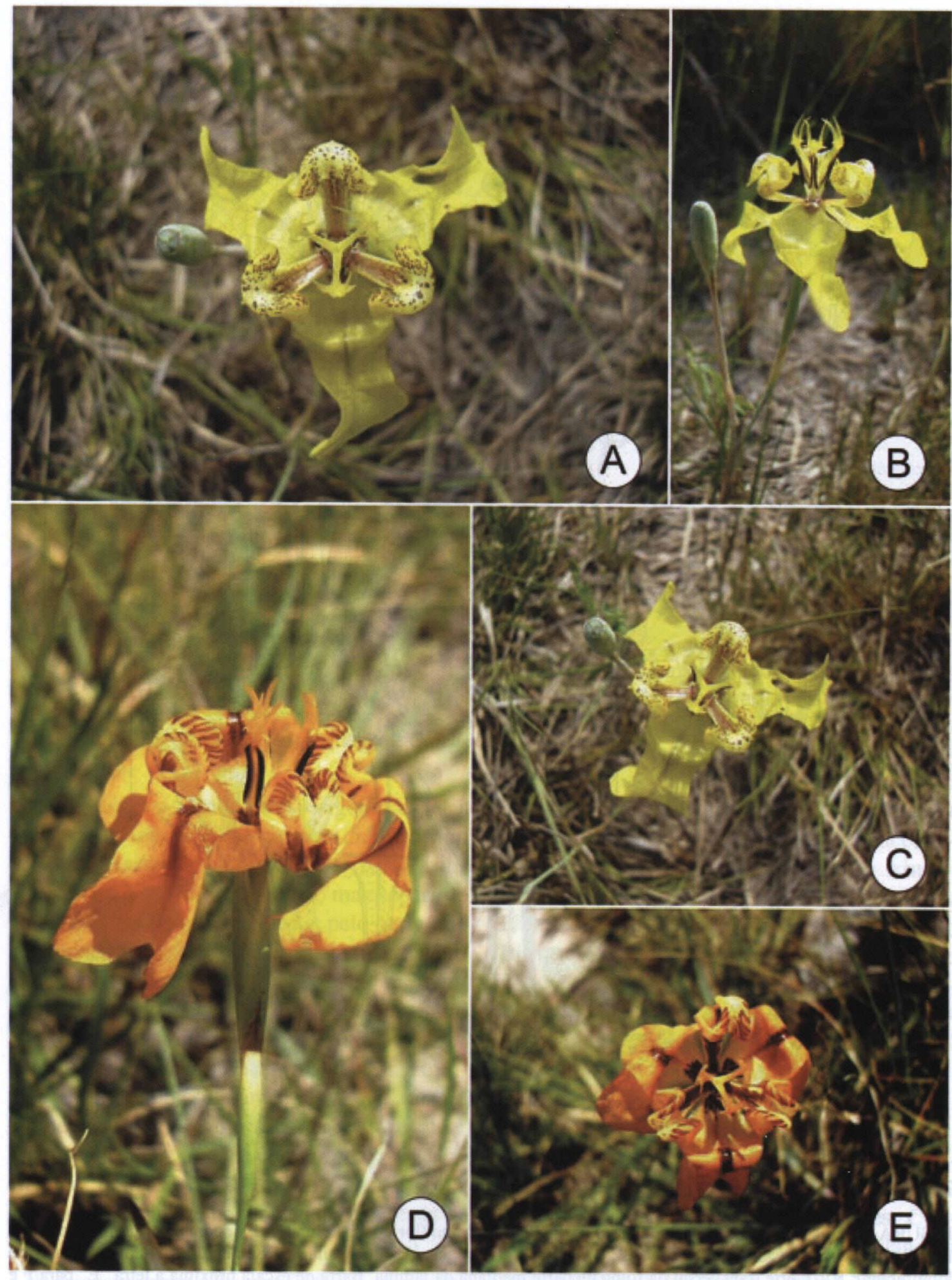

FIGURA 3 - Cypella armosa (A-C) e Cypella exilis (D-E). A - Flor em vista frontal. B - Flor em vista lateral. C - Flor em vista oblíqua. D - Flor em vista lateral. E - Flor em vista frontal. 
Tabela 1. Características relevantes na distinção de Cypella armosa e espécies afins.

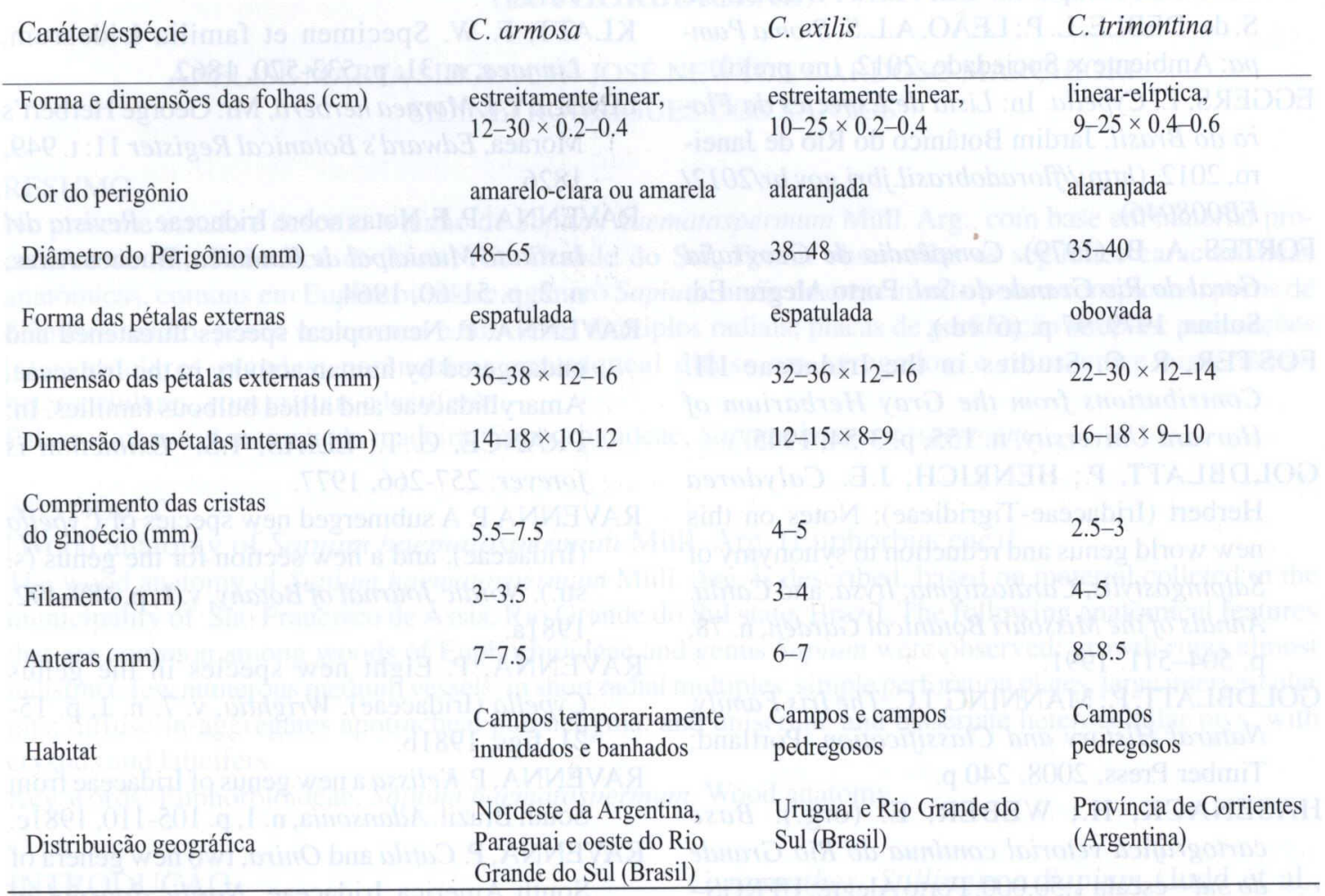

1967, A. Krapovickas \& C. L. Cristóbal 13590 (CTES); estrada Ingenio Sta. Ana. Ruta 12, XII1975, R. Martinez-Crovetto 10111 (CTES); 16 km ENE de Corrientes, Ruta 12, Ea. Las Mercedes, 10-XII-1975, C. Quarín 3293 (CTES). San Miguel: Villa Olivari, $14 \mathrm{~km} \mathrm{~W}$ de, 24-XI-1993, M. M. Arbo 6036 (CTES). San Tomé: Ruta 41, intersección con ruta 37 [27 $56^{\prime}$, $\left.56^{\circ} 30^{\prime}\right]$, en campos, tierra colorada, arenosa, 18 XI-1994, M. M. Arbo et al. 6455 (CTES). Ruta 41 , Galarza, [28 $\left.05^{\prime}, 56^{\circ} 40^{\prime}\right]$ en campo inundado, 16-XI-1994, M. M. Arbo et al. 6286 (CTES). Paraje Galarza [28 $\left.06^{\prime} 02^{\prime \prime}, 56^{\circ} 40^{\prime} 51^{\prime \prime}\right]$, campo inundable, pajonal de Andropogon lateralis, todas las piezas florales amarillas, 23XI-1999 M. M. Arboet al. 8020 (CTES).

PARAGUAI: Cordillera: frente boca rio Bermejo, orilla del estero, pajonal bajo, 14-XII1950, A. G. Schulz 7825 (CTES). Neembucu: Neembucu, Yacaré (guazu-cuá), [26 03', $\left.57^{\circ} 25^{\prime}\right]$, campo sable, terrestre, bulbe à $3 \mathrm{~cm}$ de profondeur, fleurs jaunes, fleurs fleurissent, totle matin, puis fanent a midi, 27-X-1991, $R$. Spichinger et al. 5283 (CTES, G). Presidente Hayes: Estancia la Condrina, campo inundado, hierba, flores amarillas, 26-IV-1985 R. Dure \& C. Benitez 540 (CTES, PY).

\section{REFERÊNCIAS BIBLIOGRÁFICAS}

BAKER, J. G. Systema Iridacearum. Journal of Linnean Society Botany, London, 16 (90-91): 61$179,1877$.

BAKER, J. G. Handbook of the Irideae. London: George Bells \& Sons, 1892. 248 p.

CHUKR, N. S.; CAPELLARI JR., L. Iridaceae. In: WANDERLEY, M. G. L.; SHEPERD, G. J.; MELHEM, T. S.; GIULIETTI, A. M.; KIRIZAWA, M. (Eds.). Flora Fanerogâmica do Estado de São Paulo. São Paulo: FAPESP/ RiMa, 2003. v. 3. p. 127-147. 
DEBLE, L. P. Panorama da família Iridaceae Juss. no Bioma Pampa. In: OLIVEIRA DEBLE, A. S. de; DEBLE, L. P.; LEÃO, A.L.S. Bioma Pampa: Ambiente $\times$ Sociedade, 2012. (no prelo).

EGGERS, L. Cypella. In: Lista de Espécies da Flora do Brasil. Jardim Botânico do Rio de Janeiro, 2012. (http://floradobrasil.jbrj.gov.br/2012/ FB008046).

FORTES, A. B. (1979). Compêndio de Geografia Geral do Rio Grande do Sul. Porto Alegre: Ed. Sulina, 1979.97 p. (6 $6^{\mathrm{a}}$ ed.).

FOSTER, R. C. Studies in the Iridaceae III. Contributions from the Gray Herbarium of Harvard University, n. 155, p. 3-54, 1945.

GOLDBLATT, P.; HENRICH, J.E. Calydorea Herbert (Iridaceae-Tigridieae): Notes on this new world genus and reduction to synonymy of Salpingostylis, Cardiostigma, Itysa, and Catila. Annals of the Missouri Botanical Garden, n. 78, p. 504-511, 1991.

GOLDBLATT, P.; MANNING, J.C. The Iris Family. Natural History and Classification. Portland: Timber Press, 2008. 240 p.

HASENACK, H.; WEBER, E. (org.). Base cartográfica vetorial contínua do Rio Grande do Sul - escala 1:50.000. Porto Alegre: UFRGSIB - Centro de Ecologia, 2010. 1 DVD-ROM (Série Geoprocessamento, 3).

HERBERT, W. Tigridia herberti, Mr. George Herbert's Tiger-flower. Botanical Magazine, 52 : t. $2599,1825$.

HERBERT, W. Phalocallis plumbea lead-coloured Phalocallis. Botanical Magazine, 65 (n. ser. v. 12): t. 3710, 1839.

HERBERT, W. Tigridia Herberti supra N 2599. Cypella. Botanical Magazine, 53: t. 2637 (text 2), 1839.

HERBERT, W. Calydorea. Edwards's Botanical Register, n. 29 (misc.), p. 85, 1843.

IUCN (2010). Guidelines for Using the IUCN Red List Categories and Criteria. Version 8.1. Prepared by the Standards and Petitions SubCommittee in March 2010.from:http:// intranet.iucn.org/webfiles/doc/SSC/RedList/ RedListGuidelines. (acesso em 05 de março 2012).

KLATT, F. W. Ergantz. undbericht. Zu Baker's Syst. Iridac (Larentia). Abhandlungen der NaturforschendenGesellschaftzu Halle. Halle 15: $362,1882$.
KLATT, F. W. Irideae. Flora Brasiliensis 3: 509-548, 1871.

KLATT, F. W. Specimen et familia Iridearum. Linnaea, n. 31, p. 533-570, 1862.

LINDLEY, J. Moraea herberti, Mr. George Herbert's Moraea. Edward's Botanical Register 11: t. 949, 1826.

RAVENNA, P. F. Notas sobre Iridaceae. Revista del Instituto Municipal de Botánica, Buenos Aires, n. 2, p. 51-60, 1964.

RAVENNA, P. Neotropical species threatened and endangered by human activity in the Iridaceae, Amaryllidaceae and allied bulbous families. In: PRANCE, G. T.; ELIAS, T.S. Extinction is forever: 257-266, 1977.

RAVENNA P. A submerged new species of Cypella (Iridaceae), and a new section for the genus (s. str.). Nordic Journal of Botany, v. 1, p. 489-492, 1981a.

RAVENNA, P. Eight new species in the genus Cypella (Iridaceae). Wrightia, v. 7, n. 1, p. 1521, figs, $1981 \mathrm{~b}$.

RAVENNA, P. Kelissa a new genus of Iridaceae from South Brazil. Adansonia, n. 1, p. 105-110, 1981c.

RAVENNA, P. Catila and Onira, two new genera of South America Iridaceae. Nordic Journal of Botany, v. 3, n. 2, p. 197-205, 1983.

RAVENNA, P. Flora de Paraguay: Iridaceae. Botánica Austral, n. 4, p. 1-60, 2003.

RAVENNA, P. A survey in the genus Cypella and its allies (Iridaceae). Onira, v. 12, n. 1, p. 1-11, 2009.

ROITMAN, G.; CASTILLO, J.A. Novedades taxonómicas y nomenclaturales para la flora vascular del Cono Sur de Sudamérica: nuevas combinaciones en Iridaceae. Darwiniana, San Isidro, v. 45, p. 236-241, 2007.

ROITMAN, G; MAZA, I.; CASTILLO, J.A. Iridaceae. In: ZULOAGA, F.O.; MORRONE, O.; BELGRANO, M.J. (eds.). Catálogo de las Plantas Vasculares del Cono Sur, vol. I. Monographs in Botany from the Missouri Botanical Garden, n. 107, p. 423-453, 2008.

TENORE, M. Polia bonariensis. Catalogo Orto Botanico di Napoli: 92. 1845.

THIERS, B. [atualizado continuamente]. Index Herbariorum: A global directory of public herbaria and associated staff.New York Botanical Garden's Virtual Herbarium.http://sweetgum.nybg.org/ih/. Acesso em 12/2011. 